\title{
Zanthoxylum bungeanum Oil poisoned to death:A case report
}

\author{
Yang YuXin ${ }^{1}$ \\ ${ }^{1}$ The Third Hospital of Mianyang
}

December 21, 2021

\begin{abstract}
We reported a case of oral overdose of Zanthoxylum bungeanum oil poisoning. This case indicates overdose of Zanthoxylum bungeanum oil can lead to human body poisoning and even death. At present, the poisoning mechanism and effective treatment are not clear.
\end{abstract}

\section{Hosted file}

A case report.pdf available at https://authorea.com/users/452136/articles/550274-zanthoxylumbungeanum-oil-poisoned-to-death-a-case-report 